\title{
TINGKAT PELAYANAN RUAS JALAN TEUKU UMAR DAN JALAN SETIABUDI KOTA SEMARANG DI TINJAU DARI ASPEK PERMASALAHAN KEMACETAN LALU LINTAS
}

\author{
Agung Hendra Kusuma ${ }^{1}$; Tjoek Suroso Hadi ${ }^{2}$ \\ Program Studi Perencanaan Wilayah dan Kota Universitas Islam Sultan Agung Semarang ${ }^{1), 2}$
}

\begin{abstract}
Traffic congestion is a classic problem in big cities especially in developing countries such as Indonesia. Many things can be the cause of the traffic jam, for it is necessary to research on traffic congestion as much as possible, with the hope of producing the best solution for all.

Congestion that occurs due to the activity and mixing between local and regional flows. The purpose of this study is to analyze the level of service and performance road cut Teuku Umar street and road Setiabudi, so it can be arranged alternative actions that can be done to address the problem of traffic congestion.

The method used in this research is by using Quantitative Deductive Method Rationalistic, with retrofitting Level of Service and analysis of motion control (maneuver) in order to see the level of service road and the movement of traffic in motion over Jatingaleh Region Semarang. The results of this study is the identification of the causes of traffic congestion and the suitability of the performance in the study area (Region Jatingaleh).

Level of service for road Jatingaleh area is the level of $F$ means that hampered the flow of traffic, low speed, volume over capacity, congestion often occurs at a time long enough so that it can drop to zero. In the piece Jalan Teuku Umar and Jalan Setiabudi there are several types of motion control, there are approximately 5 crossing, diverging 6, 7 merging and 3 weaving. Seeing the condition of the poor level of service in most of the observation point, of course, reduce the performance of the maneuver crossing the road.

Need for the recommendation that a new path with the added solution of the motion control analysis (maneuver) in the form of Grade Separation, can be Overpass (Flyover) or underpass.
\end{abstract}

Keywords: transportation, congestion, road, and traffic.

Kemacetan lalu-lintas merupakan masalah klasik di kota-kota besar apalagi di negara berkembang seperti di Indonesia. Banyak hal yang bisa menjadi penyebab kemacetan lalu-lintas tersebut, Untuk itu diperlukan adanya penelitian-penelitian tentang kemacetan lalu lintas sebanyak-banyaknya, dengan harapan dapat menghasilkan solusi yang terbaik bagi semua.

Kemacetan yang terjadi karena adanya aktifitas dan percampuran antar arus lokal dan regional. Tujuan dari penelitian ini adalah menganalisis tingkat pelayanan jalan dan kinerja jalan di penggal jalan Teuku Umar dan jalan Setiabudi, sehingga dapat disusun alternatif tindakan yang dapat dilakukan untuk menangani permasalahan kemacetan lalu lintas tersebut.

Metode yang digunakan pada penelitian ini yaitu dengan menggunakan Metode Deduktif Kuantitatif Rasionalistik, dengan pedekatan Level of Service dan analisis alih gerak (manuver) sehingga dapat melihat Tingkat Pelayanan Jalan dan pergerakan alih gerak lalu lintas di Kawasan Jatingaleh Kota Semarang. Hasil dari penelitian ini adalah identifikasi penyebab kemacetan lalu lintas dan kesesuaian kinerja jalan di lokasi studi (Kawasan Jatingaleh).

Tingkat pelayanan jalan untuk jalan di Kawasan Jatingaleh adalah tingkat $F$ artinya arus lalu lintas yang terhambat, kecepatan rendah, volume diatas kapasitas, sering terjadi kemacetan pada waktu cukup lama sehingga dapat turun menjadi nol. Pada penggal Jalan Teuku Umar dan Jalan Setiabudi terdapat beberapa jenis alih gerak, kurang lebih ada 5 crossing, 6 diverging, 7 merging dan 3 weaving. Melihat kondisi tingkat pelayanan yang buruk di sebagian besar titik pengamatan, tentunya manuver crossing mengurangi kinerja dari jalan tersebut.

Rekomendasi bahwa perlunya dibangun jalur baru dengan ditambah solusi dari analisis alih gerak (manuver) yang berupa Grade Separation, bisa berupa Overpass(Fly Over) atau Underpass.

Kata Kunci : transportasi, kemacetan, jalan, dan lalu lintas. 


\section{PENDAHULUAN}

Kota merupakan suatu wilayah yang menjadi pusat konsentrasi kegiatan dan pusat pelayanan dalam lingkup wilayahnya dan cenderung dapat mengalami pertumbuhan. Kota yang mengalami pertumbuhan yang sangat pesat disebabkan karena adanya aglomerasi fungsional suatu perkotaan. Pertumbuhan ini terjadi karena faktor ekonomi, politik, dan sosial budaya. Kota juga merupakan suatu sentral bisnis untuk kawasan sekitarnya. Untuk menunjang pertumbuhan suatu kota maka perlu adanya perencanaan sarana dan prasarana yang lengkap dan mendukung.

Terjadi kemacetan terutama pada jam jam dan jalan jalan tertentu. Dengan adanya gejala tersebut sudah harus difikirkan agar tidak menjadi parah dengan istilah tindakan prepentif (Alhadar,2011). Pengaturan lampu lalu lintas yang dioperasikan saat ini belum dapat mengatasi kemacetan yang sering terjadi terutama pada jam-jam sibuk (peak hour) (Wikrama, 2011). Penyebab kemacetan yang terjadi dikarenakan adanya aktivitas sehari - hari seperti bekerja dan berangkat ke sekolah. Kemacetan yang terjadi di penggal jalan Teuku Umar dan jalan Dr Setiabudi ini sering terjadi pada jam - jam masuk kantor dan pulang kantor yaitu sekitar pagi dan sore hari.

Tujuan studi ini adalah untuk menganalisis tingkat pelayanan jalan yang ada di penggal jalan Teuku Umar dan jalan Setiabudi, sehingga dapat disusun alternatif tindakan yang dapat dilakukan untuk menangani permasalahan kemacetan lalu lintas tersebut. Dengan mengetahui permasalahan sebenarnya bisa menjadi pedoman dan memberi manfaat bagi pengelolaan lalulintas trasportasi darat di Jalur Arteri primer ini khususnya dan Kota Semarang pada umumnya.

\section{METODOLOGI PENELITIAN}

Metode pendekatan yang digunakan dalam studi ini adalah Metode Deduktif Kuantitatif Rasionalistik, dimana ilmu adalah berasal dari pemahaman intelektual kita yang dibangun atas kemampuan argumentasi secara logika dengan data-data yang ada. Dengan adanya penekanan empiris dan mampu berargumentasi secara logika dan perlu dibantu dengan data yang relevan, agar produk ilmu yang melandaskan diri pada rasionalisme memang ilmu, bukan fiksi. (Muhadjir, 1996)

Penelitian ini dimulai dengan tahap sebagai berikut:

1. Analisis geometrik lintang jalan dan aktifitas di Kawasan Jatingaleh; 
2. Analisis hambatan samping;

3. Analisis kecepatan arus bebas;

4. Analisis volume arus lalu lintas;

5. Analisis kapasitas jalan;

6. Analisis tingkat pelayanan jalan;

7. Analisis alih gerak (manuver).

Data yang digunakan dalam penelitian ini berupa data primer dan data sekunder yang diperoleh melalui pengumpulan data dengan traffic counting dan pengamatan serta identifikasi secara visual tentang kondisi exsisting dilokasi penelitian.

Karakteristik Arus lalu Lintas Terdiri dari:

1. Volume adalah jumlah kendaraan yang melalui suatu titik pada suatu jalur gerak per satuan waktu, biasanya digunakan satuan kendaraan per waktu (Morlok, 1978: 189).

2. Kecepatan adalah laju perjalanan yang biasanya dinyatakan dalam kilometer per jam (Km/jam) (Hobbs, 1995: 85). Kecepatan yang akan digunakan dalam perhitungan yang akan digunakan dalam perhitungan kecepatan kendaraan adalah kecepatan arus bebas.

Kapasitas jalan adalah jumlah lalu lintas kendaraan maksimum yang dapat ditampung pada ruas jalan selama kondisi tertentu (desain geometri, lingkungan dan komposisi lalu lintas) yang dinyatakan dalam satuan massa penumpang (SMP/jam).

Hambatan samping jalan adalah dampak dan aktivitas samping ruas jalan seperti gerakan jalan Kaki, pemberhentian angkutan umum pada ruas jalan, kendaraan masuk dan keluar sisi jalan, serta kendaraan lambat yang menyebabkan penurunan kapasitas dan kinerja jalan perkotaan (MKJI, 1997). Perhitungan tingkat hambatan samping sepanjang jalan segmen jalan yang diamati.

Tingkat pelayanan jalan adalah kemampuan jalan dalam menjalankan fungsinya. Perhitungan tingkat pelayanan jalan ini dapat dihitung dengan menggunakan perhitungan level of service (LOS).

\section{HASIL DAN PEMBAHASAN}

Batasan ruang lingkup wilayah secara makro yaitu melingkupi Kecamatan Banyumanik, Gajah Mungkur dan Candisari. Adapun batasan mikronya adalah penggal jalan Teuku Umar dan jalan Setiabudi. 
Jalan ini terdapat pusat-pusat kemacetan, yang sering terjadi kemacetan pada ruas jalan Teuku Umar dan Jalan Setiabudi. Kemacetan terjadi karena adanya peningkatan aktivitas dan moda pergerakan lokal dan regional dari perdagangan, dan perkantoran baik yang terdapat disepanjang ruas jalan tersebut maupun yang berada di pusat kota.

Berdasarkan observasi di lapangan, sistem aktivitas di Kawasan Jatingaleh adalah kegiatan perdagangan dan jasa, kegiatan pemukiman, kegiatan perkantoran, pendidikan dan kegiatan-kegiatan lainnya.

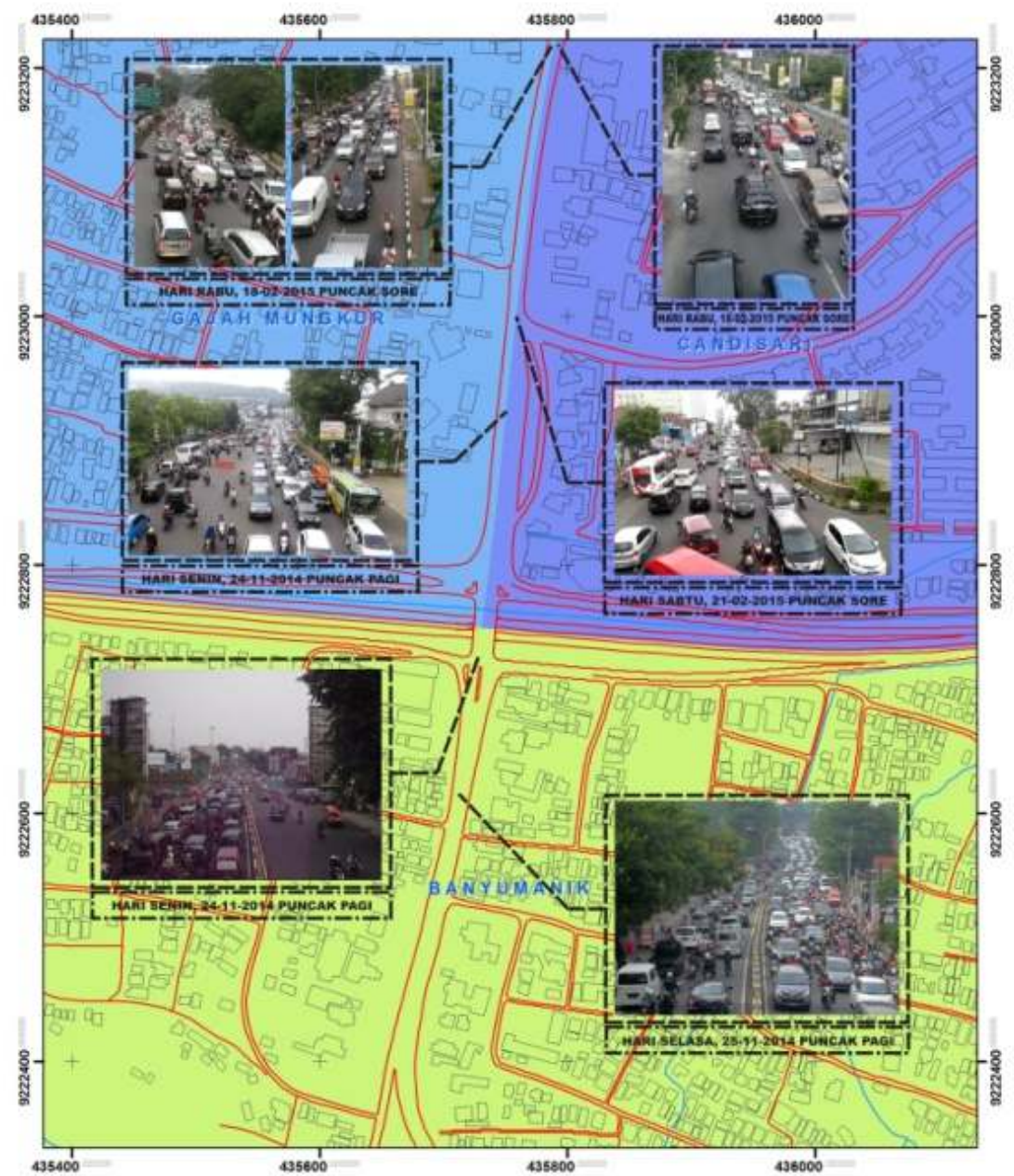

Gambar 1 Kondisi Eksisting Kawasan Jatingaleh

Hasil analisis studi penelitian antara lain :

1. Kondisi geometrik jalan yang berbeda - beda di setiap titik pengamatan. Pada titik Pengamatan pertama merupakan tipe jalan Empat lajur tak terbagi (4/2 UD), titik 
pengamatan kedua merupakan tipe jalan Enam lajur terbagi (6/2 D) dan titik pengamatan yang ketiga merupakan tipe jalan empat lajur terbagi(4/2 D). Untuk kondisi aktivitas penggal Jalan Teuku Umar dan Jalan Setiabudi berdasarkan observasi di lapangan, di Kawasan Jatingaleh terdapat kegiatan perdagangan dan jasa, kegiatan pemukiman, kegiatan perkantoran, pendidikan dan kegiatan-kegiatan lainnya.

2. Kelas hambatan samping dari nilai perhitungan pada semua titik pengamatan di penggal Jalan Teuku Umar dan Jalan Setiabudi merupakan kelas "tinggi" dengan nilai frekuensi bobot sebesar 599,1 per200m/jam(dua sisi). Frekuensi bobot ini diperoleh dari nilai rata rata titik pengamatan 1, 2, dan 3 yaitu : $(515,2+542,8+739,2) / 3=599,1$.

3. Dari hasil perhitungan kecepatan arus bebas di titik pengamatan yang pertama diperoleh hasil $40,89 \mathrm{~km} / \mathrm{jam}$, titik pengamatan kedua diperoleh hasil 49,82km/jam, dan titik pengamatan ketiga diperoleh hasil 48,96km/jam.

4. Perhitungan kapasitas jalan pada penggal Jalan Teuku Umar dan Jalan Setiabudi untuk titik pengamatan 1 adalah $\mathbf{4 7 5 0 , 2} \mathrm{smp} / \mathrm{jam}$, titik pengamatan 2 adalah $\mathbf{8 4 7 0 , 4} \mathrm{smp} / \mathrm{jam}$, titik pengamatan 3 adalah $\mathbf{5 7 6 8 , 4} \mathrm{smp} / \mathrm{jam}$.

5. Hasil perhitungan volume lalu lintas:

a. Total arus lalu lintas hari senin, 24 November 2014 di titik pengamatan 1 pada pagi hari 8375,2 $\mathrm{smp} / \mathrm{jam}$ dan sore hari sebesar 7877,6 smp/jam. Di titik pengamatan 2 pada pagi hari $8322 \mathrm{smp} / \mathrm{jam}$ dan pada sore hari sebesar $8697,6 \mathrm{smp} / \mathrm{jam}$. Di titik pengamatan 3 pada pagi hari 9927,2 smp/jam dan sore hari sebesar 8698,8 smp/jam.

b. Hari Selasa, 25 November 2014 jumlah total arus lalu lintas di titik pengamatan 1 pada pagi hari 11188,8 smp/jam dan sore hari sebesar 11001,2 smp/jam. di titik pengamatan 2 pada pagi hari 11588,8 smp/jam dan sore hari sebesar 10524,4 smp/jam. di titik pengamatan 3 pada pagi hari 11964,4 smp/jam dan sore hari sebesar 10394,8 smp/jam.

c. Hari Rabu, 26 November 2014 jumlah total arus lalu lintas di titik pengamatan 1 pada pagi hari 10124,4 smp/jam dan sore hari sebesar $10366 \mathrm{smp} / \mathrm{jam}$. Di titik pengamatan 2 pada pagi hari 10388,4 smp/jam dan sore hari sebesar 10278,4 smp/jam. Di titik pengamatan 3 pada pagi hari $11018 \mathrm{smp} / \mathrm{jam}$ dan sore hari sebesar $10014 \mathrm{smp} / \mathrm{jam}$.

d. Hari Kamis, 27 November 2014 total arus lalu lintas di titik pengamatan 1 pada pagi hari 10872,8 smp/jam dan sore hari sebesar 10334,4 smp/jam. Di titik pengamatan 2 pada pagi 
hari 11039,6 smp/jam dan sore hari sebesar $10398 \mathrm{smp} / \mathrm{jam}$. Di titik pengamatan 3 pada pagi hari 11123,2 smp/jam dan sore hari sebesar 10561,6 smp/jam.

e. Hari Jum'at, 28 November 2014 total arus lalu lintas di titik pengamatan 1 pada pagi hari $\mathbf{8 4 8 0 , 4} \mathrm{smp} / \mathrm{jam}$ dan sore hari sebesar $9870 \mathrm{smp} / \mathrm{jam}$. di titik pengamatan 2 pada pagi hari $8512 \mathrm{smp} /$ jam dan sore hari sebesar $9696,8 \mathrm{smp} / \mathrm{jam}$. di titik pengamatan 3 pada pagi hari 8952,4 smp/jam dan sore hari sebesar 9629,2 smp/jam.

f. Hari Sabtu, 21 Februari 2015 total arus lalu lintas di titik pengamatan 1 pada pagi hari 4171,6 $\mathrm{smp} /$ jam dan sore hari sebesar 4604,8 $\mathrm{smp} / \mathrm{jam}$. di titik pengamatan 2 pada pagi hari 5727,2 $\mathrm{smp} /$ jam dan sore hari sebesar 7338,4 smp/jam. di titik pengamatan 3 pada pagi hari $5652 \mathrm{smp} / \mathrm{jam}$ dan sore hari sebesar $\mathbf{5 7 0 8 , 8} \mathrm{smp} / \mathrm{jam}$.

g. Hari Minggu, 22 Februari 2015 total arus lalu lintas di titik pengamatan 1 pada pagi hari 3896,8 $\mathrm{smp} / \mathrm{jam}$ dan sore hari sebesar 4391,2 smp/jam. di titik pengamatan 2 pada pagi hari 4883,6 smp/jam dan sore hari sebesar 5518,8 smp/jam. di titik pengamatan 3 pada pagi hari 4947,2 smp/jam dan sore hari sebesar $5686 \mathrm{smp} / \mathrm{jam}$.

6. Tingkat Pelayanan Jalan.

a. Dari hasil perhitungan hari Senin menunjukkan bahwa tingkat pelayanan jalan dalam waktu puncak pagi di titik pengamatan 1 pada tingkat pelayanan "F" yang artinya Arus yang terhambat, kecepatan rendah, volume diatas kapasitas, sering terjadi kemacetan pada waktu cukup lama sehingga dapat turun menjadi nol atau bisa juga disebut arus terhambat (berhenti, antrian, macet). Pada titik pengamatan 2 menunjukkan tingkat pelayanan "E" yang artinya Arus tidak stabil, kecepatan rendah dan berbeda-beda, volume mendekati fasilitas, (tersendat - sendat). Pada titik pengamatan 3 puncak pagi dan semua titik puncak sore menunjukkan tingkat pelayanan "F".

b. Dari hasil perhitungan hari Selasa, Rabu, Kamis, dan Jum'at menunjukkan bahwa tingkat pelayanan jalan pada waktu puncak pagi dan sore di titik pengamatan 1, 2, 3 berada pada tingkat pelayanan "F".

c. Hasil perhitungan hari Sabtu dan minggu menunjukkan tingkat pelayanan jalan pada tingkat yang berbeda, dengan dominan "E" pada puncak sore, namun semuanya tidak ada pada tingkat "F",maka artinya bahwa volume kendaraan tidak ada yang melebihi dari kapasitas jalan. 


\section{Analisis Alih Gerak}

Pada penggal Jalan Teuku Umar dan Jalan Setiabudi terdapat beberapa jenis alih gerak, kurang lebih ada 5 crossing, 6 diverging, 6 merging dan 3 weaving. Solusi yang tepat untuk Kawasan Jatingaleh adalah Grade Separation, solusi jenis ini meniadakan konflik pergerakan bersilangan, yaitu dengan menempatkan arus lalu lintas pada elevasi yang berbeda pada titik konflik. Contohnya adalah persimpangan tidak sebidang.

\section{KESIMPULAN}

Hasil analisis studi kondisi geometrik dan aktifitas, hambatan samping, kecepatan, kapasitas dan volume ini berpengaruh terhadap analisis Tingkat Pelayanan Jalan, pada penggal Jalan Teuku Umar dan Jalan Setiabudi di dapat dari membandingkan volume arus lalu lintas dengan kapasitas jalan yang ada.

a. Hasil analisis pada 5 hari kerja menunjukkan bahwa tingkat pelayanan jalan dalam waktu puncak pagi dan puncak sore di semua titik pengamatan pada tingkat pelayanan "F" yang artinya Arus yang terhambat, kecepatan rendah, volume diatas kapasitas, sering terjadi kemacetan pada waktu cukup lama sehingga dapat turun menjadi nol atau bisa juga disebut arus terhambat (berhenti, antrian, macet). Namun hanya pada titik pengamatan 2 waktu puncak pagi menunjukkan tingkat pelayanan "E" yang artinya Arus tidak stabil, kecepatan rendah dan berbeda-beda, volume mendekati fasilitas, (tersendat - sendat).

b. Hasil perhitungan pada akhir pekan/weekend menunjukkan tingkat pelayanan jalan pada tingkat yang berbeda, dengan dominan "E" pada puncak sore, namun semuanya tidak ada pada tingkat "F",maka artinya bahwa volume kendaraan tidak ada yang melebihi dari kapasitas jalan.

c. Untuk Analisis Alih Gerak Solusi yang tepat untuk Kawasan Jatingaleh adalah Grade Separation, solusi jenis ini meniadakan konflik pergerakan bersilangan, yaitu dengan menempatkan arus lalu lintas pada elevasi yang berbeda pada titik konflik. 


\section{Rekomendasi}

Berdasarkan kesimpulan, maka perlu diambil langkah-langkah untuk mendapatkan ruang jalan yang optimal serta pengelolaan jalan secara efektif dan efisien sebagai upaya untuk mengatasi permasalahan lalu lintas yang terjadi. Langkah-langkah tersebut antara lain :

1. Perlunya penindakan tegas pada mobil angkutan umum yang berhenti sembarangan. Seperti pada titik pengamatan 1 yang tidak mempunyai bahu jalan sedangkan seringkali angkutan kota berhenti sembarangan.

2. Perlu adanya penyadaran masyarakat untuk menggunakan jembatan penyeberangan agar tidak mengganggu arus lalu lintas. Contohnya pada titik pengamatan 3 masih banyak pejalan kaki tidak menggunakan jembatan penyeberangan.

3. Melihat dari volume jalan yang melebihi kapasitas jalan yang ada, membuat tingkat pelayanan yang buruk. Perlu adanya penataan ruang jalan baru agar volume kendaraan sesuai dengan kapasitas jalan dan tidak terjadi tundaan.

4. Sebagian besar tingkat pelayanan jalan di semua titik pengamatan menunjukkan tingkat yang buruk, dengan nilai volume kendaraan sebagian besar hampir dua kali lipat bahkan lebih dari dua kali lipat dari kapasitas jalannya. Maka perlu dibangun jalur baru untuk menampung kelebihan volume kendaraan tersebut.

5. Menghubungkan antara perlunya dibangun jalur baru dengan solusi dari analisis alih gerak (manuver) yang berupa Grade Separation, solusi jenis ini meniadakan konflik pergerakan bersilangan dengan persimpangan tidak sebidang, bisa berupa Overpass (Fly Over) atau

\section{Underpass.}

\section{DAFTAR PUSTAKA}

Alhadar, A. (2011). Analisis Kinerja Jalan Dalam Upaya Mengatasi Kemacetan Lalu Lintas Pada Ruas Simpang Bersinyal Di Kota Palu. SMARTek, 9(4).

Muhadjir, N. (1996). Metodologi penelitian kualitatif: pendekatan positivistik, rasionalistik, phenomenologik, dan realisme metaphisik telaah studi teks dan penelitian agama. Rake Sarasin.

F.D Hobbs. (1995). Perencanaan dan Tehnik Lalu Lintas Edisi Kedua. Yogyakarta. Gajah Mada University Press. 
Morlok, Edward Klient. (1978). Pengantar Tehnik dan Perencanaan Transportasi,. Terjemahan Yani Sianipar. Jakarta: erlangga.

Wikrama, J. (2011). Analisis Kinerja Simpang Bersinyal. Jurnal Ilmiah Teknik Sipil. 